clinical problem of the assessment of pancreatic function, by secretin and other tests. The ætiology of chronic pancreatitis is not dealt with, except concerning hereditary pancreatitis. This condition is associated with a selective aminoaciduria of lysine and cystine, and it is possible that some metabolic or biochemical defect predisposes to it. Diagnostic methods, such as the value of sweat tests for cystic fibrosis, are covered admirably. It is unfortunate that the estimation of the salt content of sweat, so typically raised in children, is of so little help in adults because of overlap with the normal, though it does appear that standardisation of techniques and of the rate of flow of sweat may clarify this in the future.

The gastroenterologist, or anyone interested particularly in the pancreas will consider it worth buying. It is not a tome that can be 'swotted up' for some examination, though it will be of help to anyone whose mental image of this enigmatic organ is blurred, for it will certainly help to improve their focus. The book comes to life in the discussions which are reported verbatim. These are lucid, frank, critical, speculative, and progressive in their outlook; so that the casual reader who has merely decided to glance through the pages, will find himself reading on and learn a lot.

\section{Handbook of Clinical Cardiology}

Harold W. Salmon, M.D., M.R.c.P. Pp. viii + 184, illustrated. London: Harvey \& Blythe. 1962. 25 s.

This new book is designed for general practitioners, junior hospital doctors and students. It is a systematic, but concise account of the main branches of cardiology. The presentation is good and the style of writing is attractive, making for easy reading. The author even allows himself the occasional jest, for example, 'the bedpan is outcommoded.'

Generally speaking, the teaching is sound and, although one disagrees with some of the opinions stated, at least one knows exactly what the writer thinks.

The approach is entirely clinical, and for this reason the book will be useful to students who are making their first attempts at bedside diagnosis. Another good point is the commendable practice of giving exact doses of any drug mentioned. A mistake here is the recommendation of an initial day's dose of ' $200-300$ mg.' of phenindione (Dindevan), which is excessive. There are also some errors in the general text. For example, it is stated that the third heart sound is accentuated in mitral stenosis. How a sound caused by rapid filling of the ventricle is increased in the presence of an obstruction to filling, is not explained. And no wonder.

The section on congenital heart disease is not satisfactory, and particularly so about atrial septal defects. The vital fact that splitting of the second sound is fixed on respiration, is not even mentioned; the statement here that 'the pulmonary second sound is split' is just not good enough in a book published in 1962 .

In spite of these mistakes, this book has quite a lot to recommend it. Many teachers would be adamant that having mastered the cardiological section of a general medical text book, seekers after further knowledge should study Paul Wood's 'Diseases of the Heart and Circulation,' but there must be many doctors dealing with heart disease every day, who will be unable to take this advice, and for them, the book under review w do considerable good.

For $25 \mathrm{~s}$. and only a few hours reading, substanti庚 teaching may be obtained. The book itself is wef bound and an unusually tough quality paper is used. There are a number of E.C.G. reproductions and line diagrams, and also 10 plates of radiographs, which have not come out too badly, though the one supposed to show Kerley lines, just doesn't, at least in the reviewer? copy.

\section{Electrodiagnosis and Electromyography}

Edited by Sidney LICHT, M.D. Second Editiog Pp. xiii +470 , illustrated. New Haven, Connecticut Elizabeth Licht. 1961. \$12.00.

This publication constitutes the first of five volumes edited by Dr. Sidney Licht and called the "Physicgs Medicine Library'.

That a second and greatly expanded edition has been required less than five years after its original appearan indicates the scale and speed of recent advances in this branch of medicine. As the editor points out in his historical review, progress in this subject has unt recently been associated with major wars resultim from the surge of peripheral nerve injuries requiring assessment and treatment.

Electromyography is a very modern science dating from about 1929 when Adrian invented the coaxid needle electrode and introduced the loud speaker as method of illustrating changes in nerve and muscle potentials. It is only since the end of the Secon World War, however, that electromyography h\% become a practical routine clinical procedure, maints as a result of technological advances in the field electronics. These advances have also made possible measurements of sensory and motor conduchion velocities and their variations in physiological ofid pathological states.

To describe and critically evaluate these techniqug Dr. Licht has collected a team of international acknowledged experts. The first six chapters deal essentially with the physiological and anatomica principles concerned in electrodiagnosis. Then follo two elementary but comprehensive chapters on routime electrodiagnostic procedures, the first of these Philippe Bauwens. Wynn Parry contributes a conci? but clear explanation of the scope of ' Strength Duration Curves', and to mention other British contributors Harris writes on the significance of "Chronaxyo, Taverner on the 'Clinical application of Electromy? graphy' and Gilliatt contributes as an acknowledgegd expert on the problems of motor and sensory nerve conductions. Finally there are two highly specialized chapters on electroencephalography and electroretino. graphy.

There is a complete subject and author index an each chapter is followed by a selected bibliography. The book throughout is well produced and the diagrams are clear.

In his preface the editor says that the first edition became a standard textbook in many training programmes in the United States and elsewhere. It seeros likely that his commendable efforts will make the second edition a universal authority for all those interested in this complex, esoteric but rapidly develof ing branch of clinical medicine. 